MATEC Web of Conferences 22,01054 (2015)

DOI: $10.1051 /$ matec conf/ 20152201054

(C) Owned by the authors, published by EDP Sciences, 2015

\title{
An Algorithm and Implementation Based on an Agricultural EOQ Model
}

\author{
Zhineng $\mathrm{Hu}^{*}$, Tianyu Cao, Yazhen Chen \& Longbo Qiu \\ Department of Management Science and System Science, College of Business Management, Sichuan University, \\ Chengdu, Sichuan, China
}

\begin{abstract}
With the improvement of living quality, the agricultural supermarket gradually take the place of the farmers market as the trend. But the agricultural supermarkets' inappropriate inventory strategies are wasteful and inefficient. So this paper will put forward an inventory strategy for the agricultural supermarkets to lead the conductor decides when and how much to shelve the product. This strategy has significant meaning that it can reduce the loss and get more profit. The research methods are based on the inventory theory and the EOQ model, but the authors add multiple cycles' theory to them because of the agricultural products' decreasing characteristics. The research procedures are shown as follows. First, the authors do research in the agricultural supermarket to find their real conduction, and then put forward the new strategy in this paper. Second, the authors found out the model. At last, the authors search the specialty agriculture document to find the data such as the loss rate and the fresh parameters, and solve it out by MATLAB. The numerical result proves that the strategy is better than the real conduction in agricultural supermarket, and it also proves the feasibility.
\end{abstract}

Keywords: agricultural supermarket; EOQ; freshness; loss rate; maximal shelves; remain shelves

\section{INTRODUCTION}

In recent years, with the continuous improvement of living standards of residents, people have new demanding requirements on the quality of agricultural products and consumer convenience. Because the traditional farmers market has some drawbacks, it is gradually unable to meet people's needs due to poor facilities and inadequate infrastructure, backward management and a low degree of standardization, dirty consumer environment, low quality of agricultural products and the higher loss rate. In this context, a new type of agricultural product consumption is flooded into the consumers' eyesight, namely agricultural supermarket. Compared with the traditional farmer's market, the main features of agricultural supermarkets are: standard packaging, price tag, freedom of choice, and the electronic payment. The retail stores and the shopping malls which sell agricultural products as the main products can be called agricultural supermarkets. This study chooses the agricultural supermarkets as research subjects for three reasons. First, the general agricultural consumer market gradually focuses on agricultural supermarket, so it's necessary to study on this. Second, the difference between agricultural supermarkets' sales volume per day and farmers market is great, so if we still follow the traditional inventory strategy on agricultural supermarkets, it seems to be irrational decisions. Comparing with the farmer market, the sales of agricultural supermarkets are subject to the production, the logistics and the consumer purchasing power are more complex but *Corresponding author: 916672417@,qq.com less studied.

Domestic and international research shows that the agricultural products are perishable products, and their inventory model is based on the study of perishable products. And the core elements in the perishable products are: 1) demand, 2) freshness, 3) loss rate ${ }^{[1]}$ $\mathrm{Ha}$ and $\mathrm{Kim}^{[2]}$ analyzed the integration between the buyer and the producer by setting up a mathematical model. Yang and Wee ${ }^{[3]}$ derived the integration model between the producer and the buyer for deteriorating items. SARKER BR studied the influence of the shelve products' freshness on demand. The higher freshness of the perishable products possesses, and the greater demand will be ${ }^{[4]}$. Many documents suggest that the demand of the perishable products is closely related to the freshness. The demand function in this paper is based on these researches. Perishable products have a significant feature: decay on the quality and quantity. The Freshness and loss rate that determines the EOQ model of perishable products is different from the basic EOQ model. Decay on the quality can be measured by the freshness, and the decay on quantity is a loss rate. Ghare and Schrader were the first authors to consider the effect of decay on inventory items. They used the term "inventory decay" to describe this phenomenon, including the direct spoilage, the physical depletion and the deterioration. They developed a general EOQ type model based on constant demand with exponential decay, which could be iteratively solved, not directly ${ }^{[5]}$. Deterioration is defined by Wee ${ }^{[6]}$ as decay, damage, spoilage, evaporation, obsolescence, pilferage, and loss of 
utility or loss of marginal value of a commodity that results in decreasing usefulness from the original one. Several researchers studied a deteriorating inventory system in recent decades. In recent year, many scholars dedicated to researching the EOQ model of perishable products which is based on the freshness and the loss rate of the products. $\mathrm{Wu}{ }^{[7]}$ discussed an EOQ model with time-varying demand, considering deterioration and shortages. Lietal ${ }^{[8]}$ analyzed views on inventory management for deteriorating items. Mishra and Singh ${ }^{[9]}$ developed an inventory model with constant rate of deterioration and time-dependent demand. Yan et al ${ }^{[10]}$ developed an integrated inventory model of production for a deteriorating inventory item. Balkhi ${ }^{[11]}$ presented an optimal ordering policy for deteriorating items based on different supplier trade credits and considered a finite horizon. The Freshness and loss rate that determines the EOQ model of perishable products is different from the basic EOQ model.

The main strategy presented in this paper is several shelves for one ordering. When the manager purchases a number of agricultural products, or just shelves a section, others will be stored into the refrigerators to keep them fresh and reduce the loss. When the remains of the shelved section are few or sold out, then take out another section from the refrigerators until all the products are taken out. In the strategy, there are two stock environments leading to two pairs of freshness and loss rate which make the inventory system difficult to control. Several papers have made some research on several periods of agricultural products inventory strategy. Changyuan Yan built a model which is related to integration of multiple period inventory ${ }^{[12]}$; Bing Luo ${ }^{[13]}$ and Po-Chung Yang ${ }^{[14]}$ set up a perishable product EOQ model considering backlogging rates, demand and purchase price; Chen considered the strategy of twice shelves. When the first batch of agricultural products is with a low degree of freshness after a sales period remains few, the managers abandon the remains and shelve the second batch ${ }^{[15]}$. Singhetal considered perishable items with power demand and partial backordering ${ }^{[16]}$. Mishra and Singh put out an inventory ordering policies of delayed deteriorating items based on permissible delay in payments [17]. The documents mentioned above are involved in considering not only one period, however, no one considered the strategy of several shelves in a period which can reduce the decay of quality and quantity when the managers store most of agricultural products in most of time. The objective function is the revenue maximization.

In this paper, we proposed an agricultural products inventory strategy of several shelves for one ordering, and built a deterministic agricultural products inventory model assuming that this inventory strategy has better practical guiding significance for the agricultural supermarket. The organization of the paper is shown as follows.

\section{MATHEMATICAL MODELING AND ANALYSIS}

The mathematical model considering the integrated raw material, production and distribution is developed based on the following assumptions:

(a)The demand within the scope of the supermarkets' service is only decided by the freshness of the agricultural products shelved.

(b)The agricultural products after purchased are net worth. They are not needed to be cleaned and selected and other processing.

(c)The replenishment for buyer is instantaneous.

(d)Shortage and returns are not allowed.

(e)Deterioration of the agricultural products is considered only after they have been received into the inventory.

(f)The freshness function is exponentially distributed, and the loss rate is a constant.

The parameters are set as follows:

$\mathrm{y}:$ market size

$\theta_{1}$ : freshness pararmeters on the shelves

$\theta_{2}:$ freshness pararmeters in the refrigerator

$\beta_{1}$ : the loss rate on the shelves

$\beta_{2}$ : the loss rate in the refrigerator

$\mathrm{p}$ : price

$\mathrm{w}$ : purchase price

$\mathrm{h}_{1}$ : unit inventory costs of the agricultural on the shelves

$\mathrm{h}_{2}$ : unit inventory costs of the agricultural in the refrigerator

$\mathrm{K}$ :ordering cost

$\mathrm{C}:$ Fixed labor costs

r: Variable labor costs

The traditional demand function of the perishable products is $D(\mathrm{t})=y e^{\theta t}$, called $e^{\theta t}$ freshness. And the differential equations related to the invention function are $\frac{d I(t)}{d t}=-D(\mathrm{t})-\beta I(t), \quad$ then $\mathrm{I}(0)=\mathrm{Q} \quad(\mathrm{Q}$ is the purchase volume $)$ and $\mathrm{I}(\mathrm{T})=0$ ( $\mathrm{T}$ is the sale period). Almost all the inventory theories of agricultural products are based on the research foundation.

But in the strategy of this paper, the agricultural products are totally shelved $\mathrm{n}$ times, each amount 
is $q_{m}$. And the agricultural products which have not been shelved will suffer from the decay in the refrigerator more slightly than on the shelves. After the agricultural products on the shelves are at a certain level, there is not much left but with low freshness, and abandon the remains (Its amount is $q_{r}$ ). Managers

can decide the " $q_{m}$ " and " $q_{r}$ "to control the inventory.

The demand function of the $n$-th product shelved is $D_{n}=y e^{\theta_{2} t_{n-1}+\theta_{1}\left(t-t_{n-1}\right)}\left(t \in\left(t_{n-1}, t_{n}\right)\right)$, because it has been stored in the refrigerator for" $t_{n-1}$ ". Then the differential equations related to the invention function

are $\frac{d I(t)}{d t}=-y e^{\theta_{2} t_{n-1}+\theta_{1}\left(t-t_{n-1}\right)}-\beta_{1} I(t)$.

Solving the differential equations, it can be obtained

that $I(t)=\left(C-\frac{y e^{\left(\theta_{2}-\theta_{1}\right) t_{n-1}+\left(\theta_{1}+\beta_{1}\right) t}}{\theta_{1}+\beta_{1}}\right) e^{-\beta_{1} t}$, and

we notice that it's just the $n$-th inventory function.

And we know that $I\left(t_{n-1}\right)=q_{m}$ and $I\left(t_{n}\right)=q_{r}$.

Put them into the function, and obtain a recurrence

relations of each $t_{n}$ which are related to

$q_{m}$ and $q_{r}$

$\frac{y e^{\theta_{2} t_{n-1}}}{\theta_{1}+\beta_{1}} e^{-\left(t_{n}-t_{n-1}\right) \beta_{1}}+q_{m} e^{-\beta_{1}\left(t_{n}-t_{n-1}\right)}$

$-\frac{y}{\theta_{1}+\beta_{1}} e^{\left(\theta_{2}-\theta_{1}\right) t_{n-1}+\theta_{1} t_{n}}=q_{r}$

This is the most important equation in this paper which establishes the link between the $q_{m}, q_{r}$ and the time node to shelve. In other word, managers just need to decide how many to shelve and how many to abandon. From Figure 1 it can be analyzed that in the system of refrigerator environment and the shelves environment, freshness of the agricultural products which is firstly shelved is determined (because they are just shelved and completely fresh). Then just decide how many to shelve, and it is to be controlled that how this curve goes. Then the manager should decide when to replenish the second batch of "qm". This moment should be decided by "qr". When the inventory level is reduced to "qr", they make the decision. Since the inventory function curve of the first batch is known, "t 1 " is determinate. " $\mathrm{t} 1$ " is just the intersection of "qr" and the inventory function of first batch. The second batch of agricultural products has been stored in the refrigerator for " $t 1$ ", so their freshness is determinate. Just like the first batch, the whole function curve can be decided when the "qm" and "qr" are decided. Just as the presented equation, all the "tn" can be solved with the decided "qm", "qr" and " $\mathrm{t} 0=0$ ".

" $n$ " is the number of shelves which cannot be too large, and it can increase the decay and the inventory costs through increasing the storage time. From the fact, the sales time is limited by the operation of the agricultural supermarket. So set $n \in[1,10]$ in the solution section as follows.

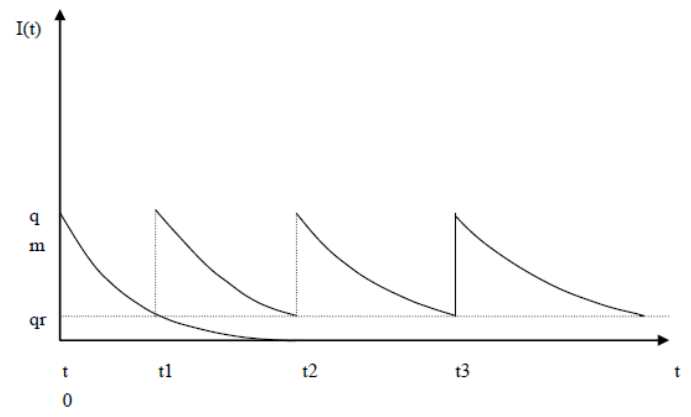

Figure 1. Inventory Level

Subjective function is a revenue maximization including several sections:

1) Inventory cost. It includes the cost in the refrigerator on the shelves. The inventory cost in the refrigerator is $H_{2}=h_{2} \sum_{i=1}^{n} \int_{0}^{t_{i-1}} q_{m}\left(1-\beta_{2}\right)^{t} d t$, because the $n$-th batch which is shelved will be stored in the refrigerator for " $t n-1$ ". The inventory cost on the shelves is $\boldsymbol{H}_{1}=h_{1} \sum_{i=1}^{n} \int_{t_{i-1}}^{t_{i}} \boldsymbol{I}(\boldsymbol{t}) d \boldsymbol{t}$. The whole inventory cost is $H=H_{1}+H_{2}$. 


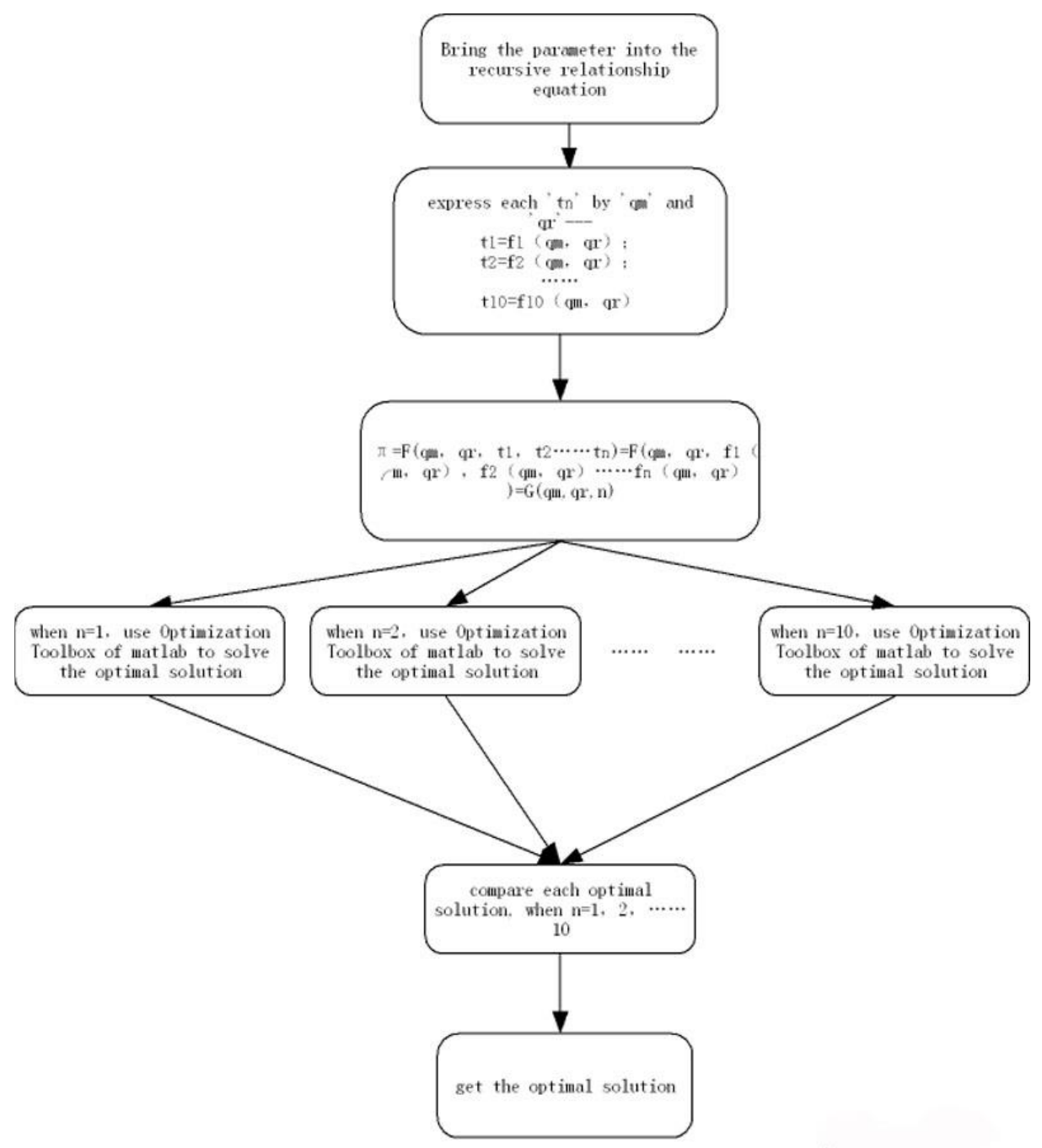

Figure 2. Flow chart of algorithm

2) Purchase cost. The n-th batch of agricultural products has suffered for "tn-1", and its number is $\frac{q_{m}}{\left(1-\beta_{2}\right)^{t_{n-1}}}$ in the beginning. So the purchase cost is $W=w \sum_{i=1}^{n} \frac{q_{m}}{\left(1-\beta_{2}\right)^{t_{i-1}}}$.

3) Ordering cost.

4) Labor cost. It includes the fixed labor cost and the variable labor cost:

$\mathrm{C}+\mathrm{rnq}_{\mathrm{m}}$ ( $\mathrm{C}$ is fixed labor cost, $\mathrm{r}$ is variable labor cost)
5) revenue.

$$
Y=p \sum_{i=1}^{n} \int_{t_{i-1}}^{t_{i}} y D_{i}(t)=p \sum_{i=1}^{n} \int_{t_{i-1}}^{t_{i}} y e^{\theta_{2} t_{i-1}+\theta_{1}\left(t-t_{i-1}\right)}
$$

The final model is shown as follows:

$$
\begin{aligned}
& \max \pi\left(q_{m}, q_{r}, n\right)=Y-W-H-K-C-n r q_{m} \\
& Y=p \sum_{i=1}^{n} \int_{t_{i-1}}^{t_{i}} y e^{\theta_{2} t_{i-1}+\theta_{1}\left(t-t_{i-1}\right)}
\end{aligned}
$$




$$
W=w \sum_{i=1}^{n} \frac{q_{m}}{\left(1-\beta_{2}\right)^{t_{i-1}}}
$$$$
H=h_{1} \sum_{i=1}^{n} \int_{t_{i-1}}^{t_{i}} I(t) d t+h_{2} \sum_{i=1}^{n} \int_{0}^{t_{i-1}} q_{m}\left(1-\beta_{2}\right)^{t} d t
$$$$
\text { s.t }\left\{\begin{array}{l}
\frac{y e^{\theta_{2} t_{n-1}}}{\theta_{1}+\beta_{1}} e^{-\left(t_{n}-t_{n-1}\right) \beta_{1}}+q_{m} e^{-\beta_{1}\left(t_{n}-t_{n-1}\right)}-\frac{y}{\theta_{1}+\beta_{1}} e^{\left(\theta_{2}-\theta_{1}\right) t_{n-1}+\theta_{1} t_{n}}=q_{r} \\
n \in N^{*} \\
q m>q r>0
\end{array}\right.
$$

\section{SOLUTION}

\subsection{Parameter setting}

Referring the document [18] , [19], the parameters are set as follows:

$\theta_{1}=-0.04$,

$\theta_{2}=-0.01$,

$\beta_{1}=0.02$,

$\beta_{2}=0.01$

$p=5$,

$\mathrm{W}=1$,

$h_{1}=0.01$,

$h_{2}=0.005$,

$y=30$

$K=800$,

$C=200$,

$r=0.05$

\subsection{Algorithm}

The recursive relationship equation is an exponential equation with parameters, which "tn" cannot be expressed by "qm" and "qr". So referring to the document [20] and [21], we use Taylor formula to deal with the exponential. The solution is shown in Figure 2.

\section{ANALYSIS}

The result is presented that when " $\mathrm{n}=5$ ", " $\mathrm{qm}=396$ " and the "qr=19.656", the subjective function is maximized. When " $n=1$ ", the model is degraded to the traditional model. And from the result, it can be seen that this strategy of several shelves for one ordering is better than the traditional strategy.

\section{CONCLUSION}

Based on the traditional QOE model, this paper puts out an innovative strategy of several shelves for one ordering, and then sets up the corresponding model. The last section is the solution. Although there are many innovations in this paper, there are many shortcomings as well. The opening time of agricultural supermarkets is regular, which is from 9:00 to 19:00, but it didn't be taken into consideration. And the approach of the Taylor formula is improper, it will be improved in the future study.

The result is shown as follows:

Table 1. Result

\begin{tabular}{llll}
\hline & qm & qr & $\pi$ \\
\hline $\mathrm{n}=1$ & 897.332 & 0 & 2333.063 \\
\hline $\mathrm{n}=2$ & 656.980 & 12.739 & 3350.598 \\
\hline $\mathrm{n}=3$ & 551.820 & 13.679 & 4155.204 \\
\hline $\mathrm{n}=4$ & 441.201 & 18.911 & 4435.529 \\
\hline$* \mathrm{n}=5$ & 396.107 & 19.656 & 4654.257 \\
\hline $\mathrm{n}=6$ & 362.185 & 24.228 & 4563.531 \\
\hline $\mathrm{n}=7$ & 320.116 & 27.376 & 3957.542 \\
\hline $\mathrm{n}=8$ & 295.004 & 31.221 & 2576.051 \\
\hline $\mathrm{n}=9$ & 261.187 & 36.991 & 1053.331 \\
\hline $\mathrm{n}=10$ & 191.346 & 40.971 & -263.943 \\
\hline
\end{tabular}

\section{REFERENCES}

[1] Wee H M. 1999. Deteriorating Inventory Model with Quantity Discount, Pricing and Partial Back ordering. International Journal of Production Economics, 59(1-3): 511-518.

[2] Wee HM. \& Jong JF. 1998. An integrated multi-lot-size production inventory model for deteriorating items. Management \&Systems, 5(1): 97-114.

[3] Yang PC. \& Wee HM. 2000. Economic ordering policy of deteriorated item for vendor and buyer: an integrated approach. Production Planning \& Control, 11(5): 474 80. 
[4] SARKER B R, MUKHERJEE S. \& BALAN C V. 1997. An Order-Level Lot Size Inventory Model with Inventory-Level Dependent Demand and Deterioration. International Journal of Production Economics, 48(3): 227-236.

[5] Ghare, P.M. \& Schrader, S.F., 1963. A model for exponentially decaying inventory. Industrial Engineering. 14(5): 238.

[6] Wee HM. 1993. Economic production lot size model for deteriorating items with partial back-ordering Computers \&Industrial Engineering; 24(3): 449-58.

[7] Wu,K.-S. Deterministic Inventory model for items with time varying demand, Weibull distribution deterioration and shortages. Yugosl. Op. Res. 12(1): 61-71.

[8] Li, R., Lan, H., Mawhinney, J.R.. A review on deteriorating inventory study. Serv. Sci. Manag. 3(1) 117-129.

[9] Mishra, V. K., Singh, L.S. Deteriorating inventory model with time dependent demand and partial backlogging. Appl. Math. Sci. 4(72): 3611-3619.

[10] Yan, C., Banerjee, A. Yang, L. An integrated production-inventory model fora deteriorating inventory item. Int. J. Prod. Econ. 133(1): 228-232.

[11]Balkhi, Z.T. Optimal economic ordering policy with deteriorating items under different supplier trade credits for finite horizon case. Int. J. Prod. Econ. 133(1), 216-223.

[12]Changyuan Yan, Avijit Banerjee. \& Liangbin Yang. 2011. An integrated production-distribution model for a deteriorating inventory item. Int. J. Production Economics, 133: 228-232.

[13]Luo Bing, Yang Shuai. \& Xiong Zhongkai. 2005. A EOQ model for deteriorating items considering backlogging rates, demand, and Purchase Price. China Management Science. 6.

[14]Po-Chung Yang. 2003. An integrated multi-lot-size production inventory model for deteriorating items. Computers \& Operations Research, 30: 671-682.

[15]Jun Chen. \& Bin Dan. 2009. The supply chain controlling based on agricultural product. Systems Engineering Theory and Practice.3.

[16] Singh, T.J., Singh, S.R., Dutt, R., An EOQ model for perishable items with power demand and partial backordering. Op. Quant. Manag. 15(1): 65-72.

[17]Musa,A. \& Sani,B.,2012.Inventory ordering policies of delayed deteriorating items under permissible delay in payments.Prod.Econ.136(1): 75-83.

[18]Huili Zheng Daqing Li. A EOQ model with time varying and purchase price. China Management Science, 2003, 11(5): 26-30.

[19]H.J. Chang. \& C.Y. Dye. 1999. An EOQ model for deteriorating items with time varying demand and partial backlogging. Journal of the Operational Research Society, 50: 1176-1182. 